\title{
T rabalho e intimidade: a constituição profissional de cuidadoras em ambiente de home care
}

Rodrigo Otávio Moretti Pires

Marcia da Silva Mazon ${ }^{* *}$

Resumo

O objetivo do artigo é analisar o trabalho do cuidado em home care. Tomando como referência Zelizer, problematizamos o ambiente de trabalho questionando a oposição binária trabalho e intimidade. A pesquisa baseia-se em entrevistas semidirigidas. Observa-se a construção de relações de trabalho a partir da negociação de laços e significados. Os principais desafios do cotidiano profissional se referem à precariedade do trabalho e ao acréscimo de outras atividades laborais exigidas (mas não negociadas) e que se realizam no silêncio da intimidade.

Palavras-chave: cuidadores, emprego, mercado de trabalho, intimidade.

* Professor do Departamento de Saúde Pública e do PPGSC, ambos na UFSC. E-mail: rodrigo.moretti@ufsc.br

** Professora do Departamento de Sociologia e Ciência Política e do PPGSP, ambos da UFSC. É coordenadora do NUSEC - Núcleo de Sociologia Econômica na mesma Universidade. E-mail: marciadasilvamazon@yahoo.com.br 


\section{W ork and intimacy: the professional constitution of caregivers in home care environment}

Abstract

The purpose of the article is to analyze the work of care in home care. Taking Zelizer as a reference we problematize the working environment by questioning the binary opposition work and intimacy. The research is based on semi-directed interviews. It is observed that the construction of labor relations comes from the negotiation of ties and meanings. The main challenges of everyday life refer to the precariousness of work and to unnegotiable labor activities additionally required taking place in the silence of intimacy.

Keywords: caregivers, employment, job market, privacy.

\section{Introdução}

Michel Foucault ao situar o nascimento do hospital lembra que ele foi, numa episteme anterior, a máquina de morrer e para lá iam os pobres condenados à morte e à espera dos últimos ritos e cuidados. É na passagem do século XVIII que os hospitais transformam-se em máquinas de cura, instrumentos terapêuticos, e são povoados pela tecnologia disciplinar da vigia e do registro da vida (iniciando nos hospitais marítimos e militares), evitando a morte. 0 médico passa a ser o principal responsável pela organização hospitalar (Foucault, 1979/2002).

A assistência à saúde é assumida como responsabilidade das instituições hospitalares consideradas ambientes seguros. No pós-guerra, e particularmente nas últimas décadas, no 
entanto, uma nova tendência toma forma ${ }^{1}$. Cresce junto com a longevidade da população a incidência de doenças crônico-degenerativas as quais demandam cuidados constantes. Surge como tendência no cuidado à saúde o deslocamento, saindo do hospital de volta aos lares. Esse novo mercado profissional é conhecido como home care (Hirschfeld e Oguisso, 2002).

Especialistas da área abordam essa modalidade como solução ao desafio do aumento constante do custo hospitalar, da mesma forma que contempla segurança, bem-estar e conforto ao paciente em seu próprio ambiente, tão bem como evita as infecções hospitalares (Hirschfeld e Oguisso, 2002). Se num momento anterior a questão do custo das aposentadorias era o único tema em pauta, nas últimas décadas se soma a ele o desafio da dependência de populações idosas cada vez mais longevas (Molinier, 2014). Nos EUA, uma em cada quatro famílias envolve-se em cuidados com um membro da família com mais de 50 anos (Zelizer, 2011, p. 142).

Igualmente no Brasil, frente ao aumento da expectativa de vida, ocorreram diversas mudanças no mercado da prestação de serviços de saúde. Esse é o caso dos serviços de atenção domiciliar,

1 A revista Seleções/Reader's Digest de abril de 1949 (condensado do Woman's Home Companion) fez uma reportagem sobre a hospitalização a domicilio. Anuncia que o serviço de assistência a domicilio pode representar para os doentes crônicos e suas famílias uma alternativa. Narra a experiência do hospital Montefiore de Nova Iorque em que a nomeada assistência médica a domicilio pode habilitar qualquer família a assumir as funções de anexo de um hospital ainda que situado a quilômetros. 0 doente crônico pode receber em casa todas as atenções e o tratamento custa-lhe apenas a quarta parte que custaria em uma enfermaria. Exemplo de uma senhora operada que não voltaria a andar. Os médicos explicam que podem enviar empregadas domésticas assalariadas que passam horas por semana ajudando nas tarefas do lar. As enfermeiras visitadoras podem treinar um membro da família. Um fisioterapeuta e um funcionário do serviço social fazem visitas regulares. A senhora do testemunho voltou a andar: "no ambiente impessoal da enfermagem não há estímulo, a pessoa tratada em casa cede lugar a outro doente" (Seleções, 1949, p. 79). 
mais comumente chamados de home care $^{2}$. A palavra care aparece frequentemente em inglês pela dificuldade de equivalente em língua portuguesa e igualmente porque os principais teóricos são americanos. Em geral, no português brasileiro é empregada a palavra cuidado 3 (Caillé, 2014, p. 43). Cresce de maneira exponencial, inclusive no Brasil, não só o número de pacientes atendidos como as tecnologias mobilizadas no cuidado deste público (PORTAL HOME CARE, 2015).

Nessa modalidade de prestação de serviço de saúde, um profissional é contratado para a função de cuidador, que integra a Classificação Brasileira de Ocupações. Em suas ações estão previstos o acompanhamento e auxílio da pessoa a ser cuidada nas atividades em que esta não consiga realizar por si, excluídas as ações previstas para a área da enfermagem (Brasil, 2008). No entanto, a função de cuidador é geralmente executada por profissionais da enfermagem (Doty, 1999). 0 cuidador age na esfera da intimida$\mathrm{de}^{4}$, relação em que ao menos uma pessoa está confiando em outra que tem acesso a suas informações (Zelizer, 2011, p. 24).

Quando o assunto são os mercados, incluídos aí os mercados de profissões, a partir das Ciências Sociais é importante consi-

2 Em 1986 foi fundada a primeira agência de home care no Brasil, a Geriatric's Home Care no Rio de Janeiro. Em 1990 foi aprovada a Lei 8.080, de 19 de setembro, que regulamenta a assistência domiciliar no Sistema Único de Saúde do Brasil. Entre 1992 e 1994 foram fundadas a ADS Home, Dal Ben e Home Doctor em São Paulo, a Pronep no Rio de Janeiro e Empresa de Home Care Saúde Lar em Porto Alegre (Portal Home Care, 2015). Em 2000 a Secretaria de Estado de Assistência Social regulamenta a assistência domiciliar a idosos pela Portaria número 2874 de 30 de agosto. Em 2002 o Conselho Federal de Enfermagem aprova a resolução 270 regulamentando as empresas que prestam serviços de enfermagem domiciliar home care.

3 Em francês a palavra evoca cuidado, preocupação, atenção, solicitude, compaixão, entre outros. Os significados oscilam entre dois extremos da dimensão técnica do atendimento e no outro o altruísmo (Caillé, 2014).

4 A intimidade pode ser entendida como emoção, atenção cuidadosa, autenticidade ou ainda como bem intrínseco. As relações íntimas variam na forma pela qual se expressam ou se inibem emoções. Intimidade costuma evocar atenção cuidadosa (Zelizer, 2011, p.24). 
derar que este tema permaneceu por décadas como exclusividade dos economistas. Desde o pacto parsoniano ${ }^{5}$, o tema dos mercados não era abordado por cientistas sociais. É o trabalho de Granovetter (1985/2003) que, retomando Weber, mostra como as ações econômicas estão enraizadas no contexto social; os atores econômicos não seriam nem átomos nem escravos da estrutura social; eles buscam além da maximização de seus lucros, reconhecimento, status, poder (Steiner, 2002). 0 que explica a ação econômica é o contexto no qual ela se insere. Esse autor é questionado pela ausência da esfera jurídica em seu quadro teórico, tão bem como o não rompimento com o ator autointeressado (Raud-Mattedi, 2005). Tomamos aqui como referência os autores Zelizer e Bourdieu que abordam os mercados como socialmente constituídos enfatizando as relações de poder e o aspecto de interatuação entre atores e instituições.

Estudiosos do home care abordam este mercado profissional segundo dois polos. De um lado, observa-se artigos discutindo o impacto dos gastos do home care para o Estado (Jacobs et al., 2013) e a qualidade de vida numa abordagem próxima da economia a qual visualiza os atores como maximizadores de oportunidades; sejam usuários, sejam agentes do Estado. De outro, a perspectiva sociológica aborda o problema do ponto de vista da tensão entre dádiva e care, destacando questões de gênero e classe social (Caillé, 2014; Debert, 2014; Hirata, 2014; Georges e Yumi, 2014; Molinier, 2014; Oliveira, 2013).

5 Desde a criação da Sociedade Americana de Sociologia em 1905 ficou estabelecida uma divisão de trabalho entre economistas e sociólogos na qual os primeiros analisariam o núcleo duro do mercado: formação de preço, mercado, contrato, dinheiro, comercio, bancos; para os sociólogos teriam ficado as 'sobras': estudos sobre família, demografia, pobreza, religião (Swedberg, 2004). Parsons, na década de 1930, reafirmou essa divisão de trabalho propondo uma sociologia que analisasse os valores que estão na base da ação econômica, a sociologia seria um acessório à ciência econômica, ao estudar as instituições econômicas (Raud-Mattedi, 2005). 
O foco deste artigo são as tensões que ganharam expressão nas últimas décadas: o processo de profissionalização das cuidadoras/cuidadores de pessoas idosas e sua interatuação com o ambiente familiar a partir da análise de experiências de cuidado remunerado na cidade de Florianópolis, no estado de Santa Catarina. 0 eixo de análise se refere à construção social desse mercado de trabalho a partir da tensão trabalho/intimidade. Propomo-nos a pensar o mercado do home care numa perspectiva institucionalista. As instituições são constituídas pelos atores ao mesmo tempo em que constituem motivações, interesses e suas visões de mundo numa perspectiva de interatuação (Bourdieu, 2005). As questões que nos interessam responder são: Quais os discursos mobilizados na legitimação do home care como trabalho remunerado? Quais ambiguidades/ tensões povoam esse processo de legitimação? Deixamos claro que este não é um estudo sobre o mercado de trabalho de cuidadores como um todo. Tal esforço exigiria dados estatísticos mais amplos quanto a frequência das empresas intermediadoras, a presença dos cuidadores nos lares e os preços médios pagos. A análise aqui pretendida é qualitativa e almeja ampliar um campo de análise.

O artigo está dividido em duas seções. Na primeira apresentamos uma abordagem sociológica dos mercados tomando como referência em particular a leitura de Zelizer sobre a emergência do care. Em seguida contextualizamos o home care e as interpretações disponíveis sobre esta atividade. Na segunda seção apresentamos os dados empíricos de pesquisa realizada em 2014 e 2015 com cuidadoras que exercem/exerceram a atividade no contexto do home care. As entrevistas foram realizadas nos anos de 2014 e 2015 na cidade de Florianópolis. Sugerimos que a atividade do home care expressa relações de poder entre classes sociais de profissionais e pacientes (conforme observado por Debert, 2014; Hirata, 2014; Georges e Yumi, 2014 e Molinier, 2014) e o acirramento desta tensão quando a atividade profissional se desenvolve no espaço privado dos lares. 


\section{Home care como 'vidas conexas': tensões e legitimação}

Discutindo o mercado do care, Zelizer (2011, 2009) lembra que existe um temor de que a introdução do dinheiro nas relações íntimas as corrompa. Do mesmo modo a recíproca é verdadeira: há o medo de que a entrada da intimidade nas relações de mercado possa gerar ineficiência: a intimidade interpessoal degradaria a atividade econômica. Segundo essa autora, embora o mundo não esteja dividido em esferas separadas de racionalidade e sentimento, esta crença é bastante difundida (Zelizer, 2011, 2009). A autora contesta essa visão de esferas separadas mostrando, na sua pesquisa sobre os significados do dinheiro, que os estadunidenses nem dão as costas a ele ao mesmo tempo em que não prejudicam suas relações pela sua busca: incorporam o dinheiro na construção de novos laços e transformam o significado do próprio dinheiro na medida em que agem (Zelizer, 2011, 1989).

Especialistas da área diferenciam relações interpessoais entre sentimentos considerados reais e simulados. Pesquisas mostram que a rotinização da expressão emocional em empregos como garçonete e comissária de bordo priva as relações sociais de seus significados podendo prejudicar a vida interior das pessoas envolvidas. Zelizer (2011) observa duas falhas nesse raciocínio. Primeiro, não há uma única pessoa em determinado corpo; sentimentos e significados variam de um relacionamento a outro. Segundo, a expressão de sentimentos torna-se uma obrigação em determinadas atividades laborais (George e Yumi, 2014 , p. 49), como o exemplo da enfermeira com pacientes terminais (Zelizer, 2011, p.25). Nesse sentido, os elementos da intimidade e relações de trabalho devem ser vistos na dinâmica de interatuação e seus significados como construídos neste processo (Zelizer, 2010a).

Zelizer (2011, p. 28) sugere que existam três posicionamentos de especialistas com relação à questão da relação entre atividade econômica e vida íntima. 0 primeiro que as considera 
como esferas separadas, como já foi mencionado: a monetização dos cuidados pessoais os corromperia. 0 segundo grupo se expressa como 'nada além de' (Zelizer, 2005). Trata-se de uma outra versão de um mercado como pura expressão de significados sem contemplar relações de poder ${ }^{6}$. 0 terceiro grupo de análises, defendido pela autora, questiona as duas primeiras posições e propõe que a mistura de intimidade e atividade econômica faz parte de uma construção e negociação de vidas conexas (Zelizer, 2011).

Conforme lembra Zelizer nenhuma família dura muito tempo sem uma extensa relação econômica entre os membros. Em qualquer cenário social: família, igreja, comunidade, múltiplos laços existem e costumam cruzar fronteiras. Esse é o caso do home care: uma relação íntima não só no espaço íntimo do paciente como de toda a família e que envolve dinheiro. Essa autora argumenta que no momento em que as relações se parecem com outras, com consequências diferentes para as partes, as pessoas esforçam-se mais para distinguir as relações, marcando seus limites. A inclusão de transações econômicas nas relações sociais geralmente amplia o esforço investido pelas pessoas na definição e disciplinamento de suas relações (Zelizer, 2011, p. 38). Interessa-nos compreender como se dá essa negociação no âmbito do home care.

Oliveira (2013), em análise de cursos para cuidadores, sugere um ambiente povoado por ambiguidades. Essa autora mostra

6 Caillé (2014) sugere a dádiva para pensar o mercado do care. Cita Gouldner e a ideia defendida por este autor de que nem sempre a dádiva pode ser retribuída. Nas situações em que há grandes assimetrias, como entre pais e filhos, adultos válidos e idosos inválidos, o cuidado dos miseráveis. Não faz sentido o doador esperar retorno, prevalece aí a benevolência. Caillé (2014) cita ainda Joan Tronto que defende o care como um processo, um trabalho. Em dimensões que se assemelham ao dar, receber, retribuir de Mauss (2003), a autora se refere aos cuidados. Para reconciliar a assimetria referente ao care com a simetria da dádiva maussiana Caillé propõe a ideia de dádiva generalizada caindo numa visão economicista do ator racional autointeressado: aquele/aquela que cuida pode perceber sua vulnerabilidade futura e antecipar os cuidados que desejará receber quando na sua velhice. 
como atributos como profissionalismo e amor surgem como elementos na definição do trabalho de cuidado. Em um dos cursos o cuidador é nomeado como membro da família e o apelo ao amor se faz presente; em outro prevalece a ideia de um profissional com direitos e deveres estabelecidos. As relações de trabalho evidenciam a tendência dos empregadores de tirar partido dos trabalhadores considerados como escravos modernos indefe$\operatorname{sos}^{7}$ (Debert, 2014).

Debert (2014) analisa a experiência do cuidado de idosos realizada na distância da família dentro das Instituições de Longa Permanência de Idosos (ILPI) ou asilos. Espaços que se conformam como espaços de mulheres com frágeis laços de solidariedade, marcado por hierarquias, desigualdade e a tensão de questões étnicas e nacionais. Para essa autora há tensões entre o processo de profissionalização calcado em desigualdades e diferentes investimentos simbólicos.

\subsection{0 desafio do care como categoria profissional}

Zelizer (2010b, 2011) defende uma dicotomia na sociedade atual em relação ao que é um trabalho genuíno e que merece remuneração, fato que negligenciaria o significado econômico de atividades que não estão inscritas no mercado de trabalho formal. Isso ocorre particularmente nos trabalhos que se realizam nos espaços de intimidade. Em sua concepção, o entendimento coletivo tanto da intimidade como do trabalho entra diretamente nessa questão, já que se trata do fundamento da compreensão de como se dão as intersecções destes espaços, assim como permite a discussão sobre os valores que guiam

7 Em pesquisa realizada por Debert (2014) na Itália, esta autora mostra como cuidadoras do Leste Europeu estavam substituindo latino-americanas e filipinas. A preferência pelas primeiras se explica por serem mais velhas, com mais alto nível de educação e, ainda, pela idade, não se ocuparem de filhos, não procurarem namorados ou festas. Características que as tornavam mais disponíveis para o trabalho. 
tanto as razões sociais como as políticas públicas que se inserem nessa temática.

Essa autora sugere pensar a intimidade como uma forma estendida de interações as quais dependem de conhecimentos particularmente recebidos, e atenção provida a partir destes, envolvendo uma relação que não é percebida em sua amplitude por uma terceira pessoa. Os conhecimentos envolvidos incluem elementos como segredos compartilhados, rituais interpessoais, informações corporais, consciência de vulnerabilidades pessoais e memórias compartilhadas de situações embaraçosas. Ao se referir à atenção, Zelizer (2010a) está indicando as condições de afeto: serviços que envolvem o corpo, a linguagem privada, o suporte emocional e a vivência de defeitos inoportunos.

As relações sociais de intimidade são dependentes de graus variados de confiança. A autora sugere a intimidade como construída em um continuum, dia a dia. Na abordagem de Zelizer (2010a), trabalho não é uma categoria de relação definida apenas pelo emprego formal (pago), mas qualquer esforço que cria valores de uso transferíveis, incluindo o valor de uso que os economistas conceituam comumente como "capital humano". Assim, ressalta que existe um trabalho íntimo, quando se aborda a intersecção entre intimidade e trabalho na vida privada de alguns para os quais outro ser humano presta serviços, sendo que a prestação de cuidados - sejam quais forem suas naturezas - está inserida nesta perspectiva laboral, independente da remuneração.

Há diferenças entre os cuidados mais íntimos, tais como os maternos, e os mais impessoais, como os aconselhamentos de farmacêuticos aos consumidores de medicamentos. 0 segundo grupo deve ser excluído da categoria de trabalho íntimo na definição da autora. 0 gradiente entre maior ou menor grau de pessoalidade no contato entre quem presta o cuidado e quem o recebe é o ponto de referência de análise. Relações que envolvem 
intimidade, mas não trabalho, também não devem ser consideradas nessa categorização de trabalho íntimo (Zelizer, 2011).

\section{T rabalho íntimo e valores}

Vinte e cinco técnicas de enfermagem que exerceram o trabalho como cuidadoras foram entrevistadas, tendo como critério desenvolverem atividade profissional junto a hospitais ou instituições sob vínculo formal trabalhista e terem desempenhado pelo menos um ano de trabalho de home care no cuidado a idosos, no município de Florianópolis (SC). Todas as entrevistas foram gravadas e transcritas na íntegra. Para a seleção das entrevistadas, empregou-se a técnica de bola de neve, em que a primeira entrevistada indicou as próximas. Foram realizadas entrevistas até que houvesse reincidência das informações, sem novos aspectos para o fenômeno investigado. As entrevistas duraram em média quarenta minutos. Todos os aspectos éticos exigidos pela legislação brasileira foram seguidos rigorosamente, e o projeto original do qual os dados foram utilizados está aprovado em Comitê de Ética em Pesquisa sobre Seres Humanos (CAAE 20234013.7.0000.0121).

O trabalho desenvolvido foi amplamente referido como "mais do que ser cuidador" ou "além dos serviços de enfermagem", justificando eticamente o envolvimento emocional que existe entre essas profissionais e seus pacientes, com o estabelecimento de laços sociais profundos. Exemplo das comparações mobilizadas: "era como se fosse meu pai", "o via como um filho", "lembrava a minha mãe" ou ainda "quando é muito velhinho, a gente vê como se fosse um bebê". Nesse sentido, a perda por ocasião do falecimento do paciente foi retratada como um momento de profunda dificul-

8 Debert (2014) e Molinier (2014) mencionam nas respectivas pesquisas na Itália e na França o contraste entre o amor pelos idosos por parte de cuidadores/cuidadoras e a oposta visão 'trabalho profissional' dos supervisores. 
dade, mesmo quando comparado com situações semelhantes em hospitais ou instituições asilares, uma vez que o desenvolvimento do trabalho íntimo no serviço de home care é mais intenso, haja vista o fato de que estas profissionais passam todo o tempo do exercício profissional exclusivamente com o mesmo paciente. Distinto dos cuidados em instituições, em que o número maior de pessoas a serem cuidadas diminui o vínculo íntimo. "É uma história com tempo definido... Definido pelo tempo de morrer".

Para as entrevistadas, é menos pessoal e menos intenso o estabelecimento dos laços sociais nas instituições frente aos do home care. A perda por falecimento foi referida com o sentimento doloroso: "Tem umas (profissionais) que se apegam tanto que parece que o paciente é parte delas".

Uma informação que chama atenção é que alguns profissionais passam por trauma tão profundo em relação à perda que ocorre adoecimento psíquico, com casos de depressão e abandono da atividade profissional.

A descrição das atividades desenvolvidas na prestação de serviços de home care revelou que a intimidade do cuidador e do paciente acontece desde a administração de medicação, a observância do regime alimentar, até atividades como corte de cabelo, banho, escolha de vestuário, acompanhamento em atividades físicas, companhia em consultas médicas, serviços bancários, entre outros, que registram uma participação íntima nos processos vivenciados e sociais cotidianos do paciente.

Alguns relatos mencionam experiências desagradáveis, principalmente nos casos de demência, em que, por exemplo, pacientes muitas vezes têm prática de masturbação diante das profissionais, ou mesmo outros em que ocorre incontinência urinária.

Em seu estudo sobre as mudanças de valores sociais e econômicos na adoção de crianças, Zelizer (1992a) defende que os valo- 
res sentimentais são fruto de construções sociais de significado sempre contextualizados historicamente. A exemplo da transformação do século XVIII para o século XX em que, enquanto o bebê economicamente "inútil" do século XIX teve de ser protegido porque era indesejado, o bebê impagável do século XX precisa de proteção, como nunca antes, porque ele está relacionado a afetividade dos adultos.

\subsection{A compra da intimidade}

Os serviços de home care são utilizados por famílias de classe média alta, segundo as entrevistadas, uma vez que o preço médio pago para as empresas que administram é de $\mathrm{R} \$ 9.000,00$ por paciente/mês.

As entrevistadas ressaltam que os quadros crônico-degenerativos, como Mal de Alzheimer, demência mental e de Parkinson, ocasionam um desgaste acentuado em que a presença de um cuidador torna-se imprescindível. A opção pelo serviço de home care por parte das famílias visa igualmente a preservação do bem-estar dos familiares. Dessa forma, procuram por um serviço que as preserve, tanto da dor emocional frente ao envelhecimento adoecido do idoso quanto das diversas manifestações emocionais, que exigiriam desta família seu isolamento social frente aos cuidados requeridos pelo paciente. Como exemplo, as cuidadoras trazem situações de conflitos ocasionados pela perda de memória dos pacientes: o esquecimento de quem é o cônjuge, os filhos, netos. "Tudo para ele é estranho". Os pacientes idosos acamados, que apresentam problemas com autonomia de mobilidade, são os que mais demandam atenção e cuidado, segundo as entrevistadas. Nesse contexto "a família chega a um ponto de exaustão em que [caso continuem no cuidado solitário] podem começar a judiar do idoso". Aqui as cuidadoras legitimam sua atuação profissional em face das limitações da família. 
As entrevistadas apontam que há mais dificuldades em lidar com a família do que com o paciente, por questões de confiança. Relatam que acabam sendo assediadas pelos diversos familiares em suas disputas internas "como se o cuidador tivesse que tomar partido", desde questões cotidianas até em brigas por herança. Ao mesmo tempo, há uma vigilância constante da família sobre o trabalho dos cuidadores, com desconfiança sobre a correção das ações técnicas desenvolvidas pelos profissionais.

Há uma tensão trazida pela ambiguidade de se constituir como um "invasor", na medida em que esses profissionais são externos à família e ao funcionamento e ritos de cada residência, e, ao mesmo tempo, representar um "membro da família". Em outros momentos, existem demarcações de segregação, como por exemplo os copos, pratos e talheres para refeições, que nas residências são destinados exclusivamente para uso do profissional, de forma que se misturam alguns aspectos, enquanto outros marcam os papéis e limites dos laços sociais. "Isso é uma divisão. Tem famílias que são assim, tem tudo dividido, o que é do paciente, da família e do cuidador. Eles não misturam. Tudo é separado".

Conforme os relatos das entrevistas quanto maior o poder aquisitivo das famílias, mais intensa a mobilização de demarcação. Isso é vivenciado como humilhação pelas entrevistadas.

\subsection{A delimitação de fronteiras}

O quarto do paciente é um território atribuído ao profissional, mas outras partes da residência são relatados como espaços em que "me sinto invadindo a intimidade", em geral onde o restante da família circula, existindo como uma demarcação de mundos, o do paciente-profissional e o da família. "Mesmo que a gente saiba onde é que está o remédio, se fica no armário da família, a gente sempre pergunta onde está, para eles não se sentirem invadidos". 
Segundo as entrevistadas, as empresas que contratam esses profissionais não oferecem qualquer tipo de preparação para lidar com o trabalho íntimo e a família dos pacientes. "Não ensinam como estar lá dentro sem ser um invasor. A gente aprende apanhando da vida, sendo xingado pela família”.

Para as entrevistadas surge uma tensão elaborada numa comparação a outras profissões: trata-se de um trabalho íntimo, que passa pela questão de oferecimento de cuidado, amor e carinho ao paciente, não há estranheza em serem remuneradas, tanto quanto um professor que ganha para ensinar, ou qualquer outro profissional que oferece serviços que apresentem elementos subjetivos.

Um cuidador/cuidadora que não seja técnico de enfermagem não está autorizado(a) por legislação a administrar medicações. Por outro lado, surge como demanda por parte da família o "trabalho doméstico". Este tipo de atividade não refere-se à ação prevista para o técnico de enfermagem, como, por exemplo, o processamento e cozimento de alimentos.

Outra diferença refere-se à remuneração. Na jornada de trabalho de 12 (doze) horas, seguida de 36 (trinta e seis) horas de folga, um técnico nessa função tem uma remuneração média mensal de $\mathrm{R} \$ 1.200,00$ (valores referentes ao ano de 2014), enquanto o cuidador recebe um salário mínimo (salário mínimo em 2014: $\mathrm{R} \$ 724,00$ ).

As empresas de home care oferecem aos contratantes a seleção e gerenciamento da agenda dos profissionais. As entrevistadas apontam que essas empresas se mantêm porque detêm o privilégio no contato com os profissionais, que as famílias não dispõem e, com isto, conseguem estabelecer-se no mercado. As empresas não estabelecem vínculos formais com os profissionais que prestam serviço. As entrevistadas declaram custear as próprias despesas, por exemplo, contribuição previdenciária como autônomas. Não realizam comprovação do rendimento, já que a 
remuneração é muitas vezes realizada por depósitos bancários, retirada direta de valores ou transferências entre pessoas físicas. "É como se fosse uma coisa clandestina, sem pagar os direitos dos funcionários".

As profissionais declaram que o fator preponderante que as levaram a abandonar esse tipo de trabalho foi a inexistência de direitos trabalhistas. Na situação de adoecimento ou férias não há remuneração.

Outro aspecto refere-se a característica de que as famílias lidam com as profissionais como alguém que as "ajuda”. A partir dessa concepção, passam lentamente a inserir pequenos trabalhos ou cuidados com crianças e outros pacientes que não se referem ao que foram contratadas. Chegando a uma situação em que progressivamente cuidam do paciente objetivo do vínculo empregatício e de mais um, no caráter de favor não remunerado, o que gera sobrecarga emocional e laboral.

As entrevistas apontam que o mercado é amplo, com muitos postos de trabalho não ocupados, sendo atrativo como oportunidade de melhoria de remuneração, no sentido de que se consegue trabalhar em duas empresas alternadamente, fazendo jornadas de 24 (vinte e quatro) horas. É um mercado predominantemente feminino, uma vez que os profissionais do sexo masculino têm maior facilidade para contratação em hospitais dada sua força física, assim como o trabalho íntimo executado por homens causa estranheza e desconforto nas famílias. "É um trabalho que precisa de vínculo. Não tem como criar vínculo se eles (familiares) têm vergonha do cuidador".

\subsection{Home care como correia de transmissão}

As entrevistadas declaram ainda que o trabalho em home care é a principal oportunidade para iniciação profissional no campo 
da enfermagem, uma vez que as empresas que administram este tipo de serviço contratam prioritariamente estudantes dos cursos técnicos do município de Florianópolis. As escolas de cursos técnicos de enfermagem selecionam e indicam para as empresas seus alunos, muitas vezes iniciantes. É ao mesmo tempo uma oportunidade no mercado de trabalho e a solução financeira que lhes permitem concluir seus cursos profissionais. Isso é o que os autores Guimaraes (2011) e Heim et al. (2011) nomeiam como correia de transmissão: uma oportunidade de trabalho, mesmo que precária, porém que funciona como primeiro contato com o mercado de trabalho formal e início para outras oportunidades profissionais menos precárias.

A precariedade em termos trabalhistas é apresentada pelas entrevistadas como uma das características desse mercado. Mesmo que o trabalho de enfermagem seja fiscalizado pelo Conselho Regional de Enfermagem, o home care se constitui num modelo de terceirização: a atividade de prestação deste serviço se situa num endereço (residência do idoso) e a empresa contratante está em outro. Essa atividade passa ao largo da fiscalização.

A inexistência de uma identidade de ação obstaculiza a construção de uma identidade profissional coesa. Os cuidadores/cuidadoras encontram-se numa encruzilhada entre empresas que os contratam e as casas onde trabalham. No cotidiano estão submetidos às singularidades de situações mais variadas, conforme já observado na atividade profissional dos vigilantes (Gadea e Cruz, 2013). Ressentem-se de um jogo atravessado por lógicas de mercado que favorecem a construção de um campo profissional subalterno e frágil o qual é permeado por condições precárias (Molinier, 2014; Hirata, 2014). A despeito da importância de sua atividade profissional possui pouca visibilidade. Os contratantes reclamam e desvalorizam seu trabalho, suas faltas, sem vislumbrar as condições precárias as quais estão submetidos. 0 fato de trabalharem individualmente e terem pouca oportunidade para se reunir com outras cuidadoras/cuidadores não fa- 
vorece a ação coletiva e a construção de identidade profissional, conforme também já observado entre vigilantes (Gadea e Cruz, 2013, p. 301).

\section{Considerações finais}

Quais os desafios para a análise de um mercado de trabalho em construção? Segundo Zelizer, o maior deles seria o de transpor as barreiras cognitivas que nos acostumaram ao apriorismo, ora do mercado como fenômeno disruptivo, ora da visão culturalista. Ambas visões apriorísticas, as quais condenam os fenômenos antes de analisá-los. A perspectiva de vidas conexas ajuda-nos a entender não só a constituição do home care como mercado de trabalho, como também as tensões envolvidas na dinâmica do seu delineamento.

A pesquisa realizada na cidade de Florianópolis/Santa Catarina trouxe algumas contribuições. Foi possível observar que os/as cuidadoras no trabalho de home care desenvolvem, negociam e reavaliam constantemente laços sociais e emocionais junto ao paciente e aos seus familiares, vivendo em tensão entre um mundo de cuidados profissionais e a intimidade das relações sentimentais e humanas. Na concepção de Zelizer (2009), o estabelecimento de relações interpessoais é inerente a vida em sociedade, de forma que mesmo nas atividades profissionais se estabelecerá a pessoalidade e a troca entre os seres humanos envolvidos, tanto em termos simbólicos como práticos e de afetividade.

Com a demanda crescente por esses serviços, mais do que a expansão do mercado, essas empresas utilizam-se do privilégio sobre o recrutamento de pessoal, que seria impossível a própria família realizar, a um preço consideravelmente alto.

Por outro lado, a seleção dos profissionais vai ao encontro de duas necessidades por parte dos cuidadores e técnicos: ou não 
podem se estabelecer no mercado por ainda encontrarem-se em processo de formação profissional, ou não conseguem, após esta formação, vínculos formais junto aos hospitais e instituições asilares. Assim, as empresas que operam serviços de home care possuem o privilégio tanto da demanda pelos serviços como pelo seu oferecimento, fatos mencionados por Zelizer com relação à negociação de crianças entre asilos e famílias interessadas no final do século XIX.

Zelizer (1992b) sugere como transações de cunho monetário são ressignificadas no sentido de acomodar os cuidados pessoais. Quando se trata de empregar um membro de fora da família no provimento dos cuidados, há um esforço maior em estabelecer fronteiras. Isso implica tomar a atividade do care como de baixo prestígio, há problemas com sua regulamentação e uma expectativa de que deveria se tratar de trabalho gratuito ou de pagamento escasso. É possível observar como essa atividade realizada de maneira isolada nas residências dificulta a organização dessas cuidadoras em torno de direitos trabalhistas.

A fala das cuidadoras entrevistadas mostra a legitimação dessa atividade secundando o ganho financeiro. 0 espaço doméstico, já preenchido por empregadas domésticas no Brasil, implica em demandar da parte das famílias em relação às cuidadoras outras atividades além do care contratado, como cuidar de crianças ou outras pessoas doentes.

\section{Ref erências}

BRASIL. Ministério da Saúde. Secretaria de Atenção à Saúde. Secretaria de Gestão do Trabalho e da Educação na Saúde. Guia prático do cuidador. Brasília (DF): Ministério da Saúde, 2008.

BOURDIEU, P. 0 campo econômico. Revista Política e Sociedade, v. 6, Florianópolis, p. 15-57, 1997/2005.CAILLÉ, A. Dádiva, care e saúde. Sociologias, Porto Alegre, v. 16, n. 36, p.42-59, 2014. 
DEBERT, GUITA G. Arenas de conflito em torno do cuidado. Tempo Social, v. 26, n.1, p. 35-45, 2014.

DOTY, P. Supportive services for the elderly and disabled. A comparison of client direct in professional management models of service delivery. Non technical summary report. U.S. Department of Health and Human Services Assistance Secretary for Planning and evolution office of disability, Aging and Long-Term Care Policy. 1999. Disponível em < http://aspe.hhs.gov/sites/default/files/pdf/73871/ihss.pdf> Acesso em 28 ago. 2015.

FOUCAULT, M. Microfísica do poder. São Paulo: Edições Graal, 2002

GADEA, C e CRUZ, S.A. 0 trabalho de vigilância nos centros comerciais, Tempo Social, v. 25, n. 1, p. 287-306, 2013.

GEORGES, I.P.H. e YUMI, G. S. Olhares cruzados: relações de cuidado, classe e gênero. Tempo Social, v. 26, n. 1, p. 47-60, 2014.

GRANOVETTER, M. Ação Econômica e Estrutura Social. O problema da incrustação. In: MARQUES, R. e PEIXOTO, J. (org.) A nova sociologia econômica. Oeiras: Celta (1985/2003).

GUIMARÃES, N. O que muda quando se expande o assalariamento (e em que o debate da Sociologia pode nos ajudar a compreendê-lo)? Dados - Revista de Ciências Sociais/RJ, v. 54, n.4, p. 633-67, 2011.

HEIM,J., ISCHER, P., HAINARD, F Le travail au noir. Pouquoi on y entre, comment on sort? Paris: L'Harmattan, 2011.

HIRATA, H. Genero, classe e raça: interseccionalidade e consubstancialidade das relações sociais. Tempo Social, v. 26, n.1, p. 61-73, 2014.

HIRSCHFELD, M; OGUISSO, T. Visão panorâmica da saúde no mundo e a inserção do home care. Revista Brasileira de Enfermagem, v.55, n.4, p.452-59. 2002.

JACOBS, J.C. LILLY M.B., Ng C, COYTE P.C. The fiscal impact of informal caregiving to home care recipients in Canada: how the intensity of care influences costs and benefits to government. Soc. Sci. Med, v. 81, p. 102-09, 2013.

MAUSS, M. Sociologia e antropologia. São Paulo: Cosac \& Naify, 2003.

MOLINIER, P. Cuidado, interseccionalidade e feminismo. Tempo Social, v. 26, n. 1 p. 17-33, 2014.

OLIVEIRA, A. M. O cuidado de idosos em múltiplas abordagens: um estudo comparativo entre cuidadores formais e familiares. VII Congresso Latino-americano de estudos do trabalho. 0 trabalho no século XXI. Mudanças, impactos e perspectivas. GT 05: Trabalho de Cuidado. 2013. Disponível em <http://congressoalast.com/wp-content/uploads/2013/08/208.pdf> Acesso em 13 fev. 2017. 
PORTAL HOME CARE, 2015 http://portalhomecare.com.br/historia-do-home-care/ Acesso em 01 out. 2015.

RAUD-MATTEDI, C. A construção social do mercado em Durkheim e Weber. Análise do papel das instituições na sociologia econômica clássica. Revista Brasileira de Ciências Sociais - RBCS, vol. 20, n.57, p. 127-42, 2005.

STEINER, P. Encastrements et sociologie économique.In: Hault, Isabelle. La construction sociale de l'entreprise: autour de travaux de Mark Granovetter, Ed. EMS: Colombelles, 2002.

ZELIZER, V. A. A negociação da intimidade. Petrópolis, RJ: Vozes, 2011.

Caring Everywhere. In:BORIS, Eileen; PARREÑAS, Rhacel Salazar. (org.). Intimate labors: culture, technologies, and politics of care. Stanford (California): Stanford University Press, p.267-79, 2010a.

A economia do care. Civitas, vol.10, n.3,p. 376-91, 2010b.

Dualidades perigosas. Mana, v. 1, n.15, p. 237-56, 2009.

Culture and Consumption. In: Smelser, N.; Swedberg, R. (eds) The hanbook of economic sociology. 2a ${ }^{\text {a }}$ Ed. Princeton UP, p. 331-54, 2005.

The social meaning of money: 'special monies'. American Journal of Sociology, v. 95, n. 2, p. 342-77, 1989.

Repenser le marché: la construction sociale du « marché aux bébés» aux Etats-Unis, 1870-1930. Actes de la recherche en Sciences Sociales, n. 94, p.03-26, 1992a.

Human values and the Market : the case of Life Insurance and Death in 19th-Century America. In: GRANOVETTER, Mark; SWEDBERG, Richard. The sociology of economic life. Boulder: Westview Press, 1992b.

Recebido em 24/02/2017

Aprovado em 31/05/2017 